\title{
Genetic Analyses of Gynogenetic Haploid Production in Onion
}

\author{
Borut Bohanec and Marijana Jakše \\ Biotechnical Faculty, University of Ljubljana, Jamnikarjeva 101, 1000 Ljubljana, Slovenia \\ Michael J. Havey ${ }^{1}$ \\ Agricultural Research Service, U.S. Department of Agriculture, Department of Horticulture, 1575 \\ Linden Drive, University of Wisconsin, Madison, WI 53706
}

ADDITIONAL INDEX wORDS. Allium cepa, haploidy, inbreeding, inheritance

\begin{abstract}
The production of doubled haploid plants is desirable as an alternative to sexual inbreeding of longer-generation crops. Onion (Allium cepa L.) is a biennial plant and amenable to the production of gynogenic haploids. Although a strong population effect has been observed for gynogenic haploid production, there is no report describing the genetic basis of greater haploid production in onion. We evaluated over years the frequency of haploid production among onion inbreds and identified lines showing significantly $(P<0.01)$ greater production of haploids. The onion inbreds, B0223B and B2923B, produced the highest mean frequencies of haploids so far reported. Hybrid families from crosses of B2923B with inbreds having relatively low haploid production showed significantly higher haploid production than the low-producing parent and significantly lower haploid production than B2923B. Plants from B0223B and B2923B with established rates of haploid production were testcrossed and/or self-pollinated. The $F_{1}$ family from B1717A-1 X B2923B-3 showed rates of haploid production slightly greater than the low parent (B1717A-1) and significantly less than the high parent (B2923B-3). Self-pollination of plants from B2923B showing relatively high rates of haploid production generated $S_{1}$ progenies also producing relatively high frequencies of haploids. Selfed progenies from plant B2923B-6 showed a high mean rate of haploid production $(56.8 \% \pm 14.5 \%)$ and, more importantly, the highest level of haploid production $(\mathbf{8 2 . 2 \%})$ reported for any single onion plant. These results indicate that relatively high haploid production, at least for B2923B, was quantitatively inherited with dominance towards low production. We suggest $S_{1}$ family selection as an effective method to increase gynogenic haploid production of onion populations.
\end{abstract}

Haploid plants possess the chromosome number of the gametophyte and, after chromosome doubling, produce sporophytic plants homozygous at all nuclear loci. The extraction and chromosome doubling of haploids has been reported for many crops (Khush and Virmani, 1996). The production of doubled haploid plants is especially desirable as an alternative to sexual inbreeding of longer-generation crop plants, in which the production of inbreds can take many years. Onion (Allium cepa L.) is a biennial vegetable requiring two years per generation. Onion inbreds are often produced by inbreeding for five or more generations, requiring at least 10 years of time and resource investments. However onion plants can rarely be self-pollinated past the $S_{3}$, due to significant inbreeding depression and poor seed yield, and onion breeders will often alternate generations of self-pollination with mass pollinations among a small number of full-sib progenies (Havey, 1993). The production of onion inbreds via haploidy would reduce the time of inbred development to relatively few years and apply strong selection pressure against deleterious recessive alleles. Another advantage of doubled haploid onion is that completely homozygous inbred lines should experience no genetic changes due to selection or drift when inbred lines are grown at different locations to produce hybrid seed.

There are no reports of successful androgenic production of onion haploids. Campion and Alloni (1990), Campion et al.

Received for publication 16 Sept. 2002. Accepted for publication 21 Feb. 2003 . Names are necessary to report factually on available data; however, the USDA neither guarantees nor warrants the standard of the product, and the use of the name by USDA implies no approval of the product to the exclusion of others that may also be suitable. The technical help of Branka Juvancic, Viktorija Dolenc, and Mark Petrashek is gratefully acknowledged. This research was supported in part by a grant from the US-Slovene research project 95/10-02-ARS-13.

1To whom correspondence should be addressed; e-mail mjhavey@facstaff.wisc.edu.
(1992), Keller (1990), and Muren (1989) successfully developed procedures for the production of gynogenic onion haploids. Subsequently, other research groups made improvements on these techniques to increase the production of gynogenic onion haploids, including altered media composition (Bohanec et al., 1995; Campion et al., 1992; Jakše et al., 1996; Martinez et al., 2000; Michalik et al., 2000a), growth conditions of donor plants (Michalik et al., 2000b; Puddephat et al., 1999), and simplified induction protocols (Bohanec and Jakše, 1999). Presently the most efficient method is based on plating whole onion flowers without subcultivation to induce the production of haploid plants from cells of the female gametophyte, avoiding laborious ovule extractions and making possible the large-scale production of gynogenic onion haploids.

Since the first reports of gynogenic haploids in onion, a strong cultivar or population effect has been described (Javornik et al., 1998). Onion populations generally show very low rates of haploid production, with frequencies ranging from $0 \%$ to $3 \%$ (Bohanec and Jakše, 1999; Geoffriau et al., 1997). This remains one of the main constraints to widespread extraction of haploids for the production of onion inbreds. However specific onion populations, such as 'IG31' at $17.4 \%$ (Geoffriau et al., 1997); 'Rocket $\mathrm{F}_{1}$ ' at 22.6\%, 'XPH3371' at 12.4\%, 'B0223B' at 18.6\%, and 'B2923B' at 19.3\% (Bohanec and Jakše, 1999); and '601A' at $10.0 \%$ (Michalik et al. 2000a) have shown significantly higher rates of haploid production. These studies documented higher haploid production rates of specific populations, but generally did not estimate any genetic or environmental effects on haploid production in onion. Geoffriau et al. (1997) evaluated mean haploid production of numerous onion populations and revealed inconsistent performances over years. In this study, we evaluated over years the frequency of haploid production among onion inbred 
lines, identified lines showing significantly higher production of haploids, and evaluated self-pollinated and testcross progenies for the ability to produce onion haploids.

\section{Materials and Methods}

A set of onion inbreds developed in the United States public sector (Table 1) were chosen to evaluate haploid production. For bulb production, seed was sown in the spring at Palmyra, Wis., on high organic soils. Plants were grown under normal production conditions typical for these soils and bulbs were harvested in September of the same year. Bulbs were cured using forced air at $40{ }^{\circ} \mathrm{C}$ for 1 week and stored at $6{ }^{\circ} \mathrm{C}$ until shipment or flowering. In November or December of the production year bulbs were shipped by overnight express to Ljubljana, Slovenia, and stored at $6{ }^{\circ} \mathrm{C}$. In February of the following year, bulbs were planted in the greenhouse for flowering. Individual flowers were cut prior to dehiscence from umbels in May and June of each year; inoculation and culture conditions were described earlier (Bohanec and Jakše, 1999). Elongation medium used for sprouted gynogenic embryos was composed of half strength BDS medium (Dunstan and Short, 1977) supplemented with $30 \mathrm{~g} \cdot \mathrm{L}^{-1}$ glucose and $7 \mathrm{~g} \cdot \mathrm{L}^{-1}$ agar (Fischer, Fair Lawn, N.J.) at pH 6.0. Emergence of gynogenic embryos was scored weekly from July to October of each year. The proportion of embryos formed per petri dish containing at least 30 flower buds was used as the experimental unit. Ploidy levels of putative haploid plants were established using flow cytometry as previously described (Bohanec and Jakše, 1999). Onion crosses were completed in Madison, Wis. as described by Pike (1986). Statistical analyses were completed using Proc GLM of SAS (SAS, 1990) treating onion populations as random variables.

\section{Results and Discussion}

The inbred lines, B0223B and B2923B, were reported by Bohanec and Jakše (1999) to produce among the highest frequencies of gynogenic haploids. Additional evaluations in 1997 and 1998 were in agreement with previous studies; B0223B and B2923B showed significantly $(P<0.01)$ higher haploid production than all the other inbreds and consistently produced the highest numbers of haploids among all onion germplasms evaluated by numerous groups to date. The other inbreds evaluated at the same time (B1828B, B2117B, B2133B, B2371C, MSU611-1B, MSU826B MSU2399B, MSU2935B, W52B, W101B, W205B, and W404B) have similar origins and levels of inbreeding (Havey, 1991) and produced relatively low frequencies of haploids (Table 1). B2923B was developed from one $\mathrm{S}_{1}$ family from the synthetic population 'Iowa Yellow Globe 53' and was released in 1983 by the USDA and Michigan and Wisconsin Agricultural Experiment Stations (Havey, 1991). B0223B is an unreleased inbred line selected from the cross of MSU5785B with the high haploid-producing inbred B2923B.

To assess the environmental or physiological effects on haploid production from specific plants, we flowered the same onion bulbs from B0223B and (B2923B x B1717B) over two consecutive years and evaluated for haploid production. Although differences in relative haploid production from the exact same plants were observed across years (Table 2 ), these plants produced significantly $(P<0.01)$ higher numbers of haploids than the low producing lines (Table 1). However the simple correlation of haploid production by the same plant over the 2 years was -0.193 , revealing relatively large nongenetic effects on the production of haploids, at least for these plants. The inconsistent production of haploids over years was also reported by Geoffriau et al. (1997).

Table 1. Mean percent gynogenic haploid production and phenotypic ranges for inbred onion populations evaluated over years.

\begin{tabular}{|c|c|c|c|c|c|}
\hline Population & Year & $\begin{array}{c}\text { Plants } \\
\text { flowered } \\
\text { (no.) }\end{array}$ & $\begin{array}{c}\text { Flowers } \\
\text { plated } \\
\text { (no.) }\end{array}$ & $\begin{array}{c}\text { Haploids (\%) } \\
\pm \mathrm{SD}\end{array}$ & $\begin{array}{c}\text { Lowest - } \\
\text { highest } \\
\text { production }(\%)\end{array}$ \\
\hline$\overline{\mathrm{AC} 43^{\mathrm{z}}}$ & 1997 & 6 & 1350 & $0.6 \pm 0.6$ & $0-1.3$ \\
\hline B0223B & 1997 & 2 & 380 & $32.9 \pm 21.5$ & $24.1-54.5$ \\
\hline B0223B & 1998 & 10 & 2220 & $23.2 \pm 23.9$ & $0.5-67.5$ \\
\hline B1717A & 1998 & 4 & 1440 & $1.9 \pm 5.0$ & $0.2-10.6$ \\
\hline B1828A & 1998 & 9 & 3510 & $1.4 \pm 0.8$ & $0-2.2$ \\
\hline B1828B & 1998 & 9 & 3180 & $0.8 \pm 1.4$ & $0-4.4$ \\
\hline B2117B & 1997 & 5 & 1155 & $0.4 \pm 0.5$ & $0-1.2$ \\
\hline B2133B & 1997 & 4 & 1845 & $4.4 \pm 2.8$ & $1.1-7.9$ \\
\hline B2371C & 1998 & 3 & 1410 & $1.4 \pm 1.1$ & $0-2.2$ \\
\hline B2371C & 1999 & 19 & 10786 & $1.8 \pm 1.7$ & $0.3-8.1$ \\
\hline B2923B & 1998 & 9 & 2940 & $20.7 \pm 14.2$ & $11.7-58.3$ \\
\hline B2923B & 1999 & 17 & 9453 & $25.3 \pm 13.3$ & $2.1-54.7$ \\
\hline BYG15-23z & 1997 & 10 & 3840 & $1.5 \pm 1.2$ & $0.3-4.0$ \\
\hline MSU2399B & 1998 & 10 & 2490 & $4.2 \pm 4.5$ & $1.3-14.3$ \\
\hline MSU2935B & 1999 & 18 & 5786 & $6.2 \pm 4.9$ & $0.8-17.9$ \\
\hline MSU2935B & 2000 & 9 & 2250 & $7.7 \pm 3.6$ & $2.9-14.3$ \\
\hline MSU611-1B & 1997 & 5 & 2160 & $2.9 \pm 3.7$ & $0.6-9.3$ \\
\hline MSU826B & 1998 & 6 & 2070 & $0.7 \pm 1.5$ & $0-3.8$ \\
\hline W101B & 1997 & 5 & 2265 & $2.5 \pm 1.1$ & $0.8-3.7$ \\
\hline W205B & 1997 & 5 & 750 & $1.1 \pm 1.6$ & $0-4.0$ \\
\hline W404B & 1997 & 5 & 1140 & $1.1 \pm 0.8$ & $0.2-1.9$ \\
\hline W52B & 1997 & 5 & 2340 & $1.2 \pm 0.7$ & $0-1.6$ \\
\hline
\end{tabular}

zAC43 and BYG15-23 are parents of an onion mapping family (King et al. 1998). Origins of the other onion populations were described by Havey (1991) and Goldman et al. (2000). 
Table 2. Percent gynogenic haploid production from the same onion plants evaluated over 2 consecutive years.

\begin{tabular}{lccc}
\hline Plant & Year & $\begin{array}{c}\text { Flowers } \\
\text { cultured (no.) }\end{array}$ & $\begin{array}{c}\text { Haploid } \\
\text { production (\%) }\end{array}$ \\
\hline B0223B-106 & 1998 & 90 & 46.7 \\
B0223B-106 & 1999 & 719 & 41.3 \\
B0223B-108 & 1998 & 270 & 44.4 \\
B0223B-108 & 1999 & 938 & 21.2 \\
(B2923B x B1717B)-83 & 1998 & 360 & 49.4 \\
(B2923B x B1717B)-83 & 1999 & 540 & 17.4 \\
\hline
\end{tabular}

Hybrid families from crosses of B2923B with inbreds showing relatively low haploid production (B2371C and B1717B) were evaluated to determine if any hybrid families showed significantly greater haploid production. B2923B repeatedly showed relatively high frequencies of haploid production in the same years as the hybrids were evaluated (Table 1). All hybrid families with B2923B as one of the parents showed significantly higher frequencies of haploids over that of the low-producing parent and significantly lower haploid production than B2923B (Table 3). $\mathrm{F}_{1}$ progenies produced fewer haploids than the mean performance of B2923B, indicating that the relatively high haploid production, at least for B2923B, may be quantitatively inherited with some degree of dominance for low haploid production.

Because the crosses reported in Table 3 were between random plants from each inbred line, we cannot distinguish between the haploid production capability of an individual from variation among individuals within the inbred. Sampling error likely contributes to variation for haploid production among individual onions within a population. Onion shows severe inbreeding depression and onion inbreds often retain significant levels of heterozygosity (King et al., 1998), contributing to the genetic diversity among individual bulbs within an inbred line. To address this concern, we crossed and self-pollinated plants from B0223B and B2923B with established rates of haploid production. The $\mathrm{F}_{1}$ family from
B1717A-1 x B2923B-3 showed rates of haploid production greater than the low producing parent (B1717A-1) and less than the high producing parent (B2923B) (Table 4). Self-pollination of bulbs from B2923B with high rates of haploid production produced $S_{1}$ progenies with relatively high rates (Fig. 1, Table 4). Selfed progenies from plant B2923B-6 showed a high mean rate of haploid production (53.6\%) and, more importantly, the highest level of haploid production $(82.2 \%)$ ever reported for a single plant. Two plants from B0223B with relatively low rates of haploid production $(0.5 \%)$ produced selfed progenies with relatively high mean rates of haploid production (Table 4). Parent-offspring regression of mean haploid production of progenies over parents was not significant $(P<0.08)$, indicating that nonadditive genetic variation was important. These results are consistent with the results of the interline crosses, in which a relatively high rate of haploid production was quantitatively inherited with low haploid production showing dominance.

The inbred line B2923B showed a high rate of mean haploid production (Table 1) and this trait was heritable (Tables 3 and 4). One selfed progeny from B2923B gave the highest level of haploid production ( $82.2 \%$ ) ever reported for a single plant. Importantly this is a publicly available male-fertile inbred line released by the USDA in 1983 (Havey, 1991). Seed of this inbred can be requested from M.J. Havey for future onion haploid research. This is in contrast to highly regenerative hybrid populations, such as 'Rocket $\mathrm{F}_{1}$ ' or 'XPH3371', which are commercial hybrids and no longer available.

Our evaluations establish that gynogenic haploid production in onion has a genetic basis with significant nonadditive and environmental effects, in agreement with observations with other plants ( $\mathrm{He}$ et al., 1998; Hou et al., 1994; Zhou and Konzak 1992). Even poorly haploid-producing inbred lines of onion possessed rare individuals with higher rates of haploid production(Table 1). Recurrent selection increased haploid production in maize (Marhic et al. 1998). Based on our observations, we propose $S_{1}$ family selection as an effective

Table 3. Mean percent gynogenic haploid production and phenotypic ranges for $F_{1}$ and $F_{2}$ progenies from crosses of inbred lines showing poor haploid production (B1717B and B2371C) with the high haploid-producing inbred B2923B.

\begin{tabular}{|c|c|c|c|c|c|c|}
\hline Families $^{z}$ & Generation & Year & $\begin{array}{c}\text { Donor } \\
\text { plants (no.) }\end{array}$ & $\begin{array}{c}\text { Flowers } \\
\text { cultured } \\
\text { (no.) }\end{array}$ & $\begin{array}{c}\text { Haploid } \\
\text { production }(\%) \\
\pm \mathrm{SD}\end{array}$ & $\begin{array}{c}\text { Lowest - } \\
\text { highest \% } \\
\text { haploid production }\end{array}$ \\
\hline B1717B x B2923B & $\mathrm{F}_{1}$ & 1998 & 9 & 2070 & $17.5 \pm 14.2$ & $0-39.2$ \\
\hline В1717B x B2923B & $\mathrm{F}_{1}$ & 2000 & 6 & 1943 & $8.9 \pm 3.1$ & $5.0-12.2$ \\
\hline B2371C x B2923B & $\mathrm{F}_{1}$ & 1998 & 8 & 3600 & $13.5 \pm 7.1$ & $2.7-25.6$ \\
\hline B2371C x B2923B & $\mathrm{F}_{1}$ & 2000 & 7 & 3180 & $5.2 \pm 3.1$ & $1.1-9.1$ \\
\hline B2371C x B2923B & $\mathrm{F}_{2}$ & 2000 & 10 & 3960 & $4.5 \pm 2.2$ & $1.7-7.8$ \\
\hline B2923B x B1717B & $\mathrm{F}_{1}$ & 1998 & 6 & 2370 & $8.7 \pm 18.2$ & $1.9-49.4$ \\
\hline В2923B $\times$ B1717B & $\mathrm{F}_{2}$ & 2000 & 8 & 3150 & $7.8 \pm 7.9$ & $1.3-25.7$ \\
\hline B2923B x B1717B & $\mathrm{F}_{2}$ & 2000 & 8 & 2903 & $3.4 \pm 2.4$ & $0-8.1$ \\
\hline
\end{tabular}

${ }^{2}$ For relative production frequencies of specific inbred lines, see Table 1.

Table 4. Mean gynogenic haploid production and phenotypic ranges for $S_{1}$ and $F_{1}$ families from onion plants with previously established rates of haploid production.

\begin{tabular}{|c|c|c|c|c|c|c|}
\hline Family & $\begin{array}{l}\text { loid production } \\
\text { of parental } \\
\text { plants }(\%)\end{array}$ & Generation & $\begin{array}{l}\text { Progeny } \\
\text { (no.) }\end{array}$ & $\begin{array}{l}\text { Flowers } \\
\text { (no.) }\end{array}$ & $\begin{array}{c}\text { Haploid } \\
\text { production }(\%) \\
\pm \mathrm{SD}\end{array}$ & $\begin{array}{l}\text { Lowest - highest } \% \\
\text { haploid production }\end{array}$ \\
\hline B0223B-2 & 0.5 & $\mathrm{~S}_{1}$ & 18 & 3600 & $28.6 \pm 14.6$ & $1.7-63.7$ \\
\hline B2923B-3 & 24.7 & $\mathrm{~S}_{1}$ & 20 & 4680 & $24.3 \pm 10.0$ & $5.0-43.0$ \\
\hline B2923B-4 & 36.7 & $\mathrm{~S}_{1}$ & 23 & 6473 & $17.7 \pm 8.6$ & $2.5-39.9$ \\
\hline B0223B-5 & 44.4 & $\mathrm{~S}_{1}$ & 13 & 2520 & $15.8 \pm 9.0$ & $1.7-32.9$ \\
\hline B2923B-6 & 58.3 & $\mathrm{~S}_{1}$ & 23 & 5580 & $56.8 \pm 14.4$ & $20.0-82.2$ \\
\hline B1717A-1 x B2923B-3 & $0.2,24.7$ & $\mathrm{~F}_{1}$ & 22 & 5640 & $5.1 \pm 3.1$ & $0-11.1$ \\
\hline
\end{tabular}



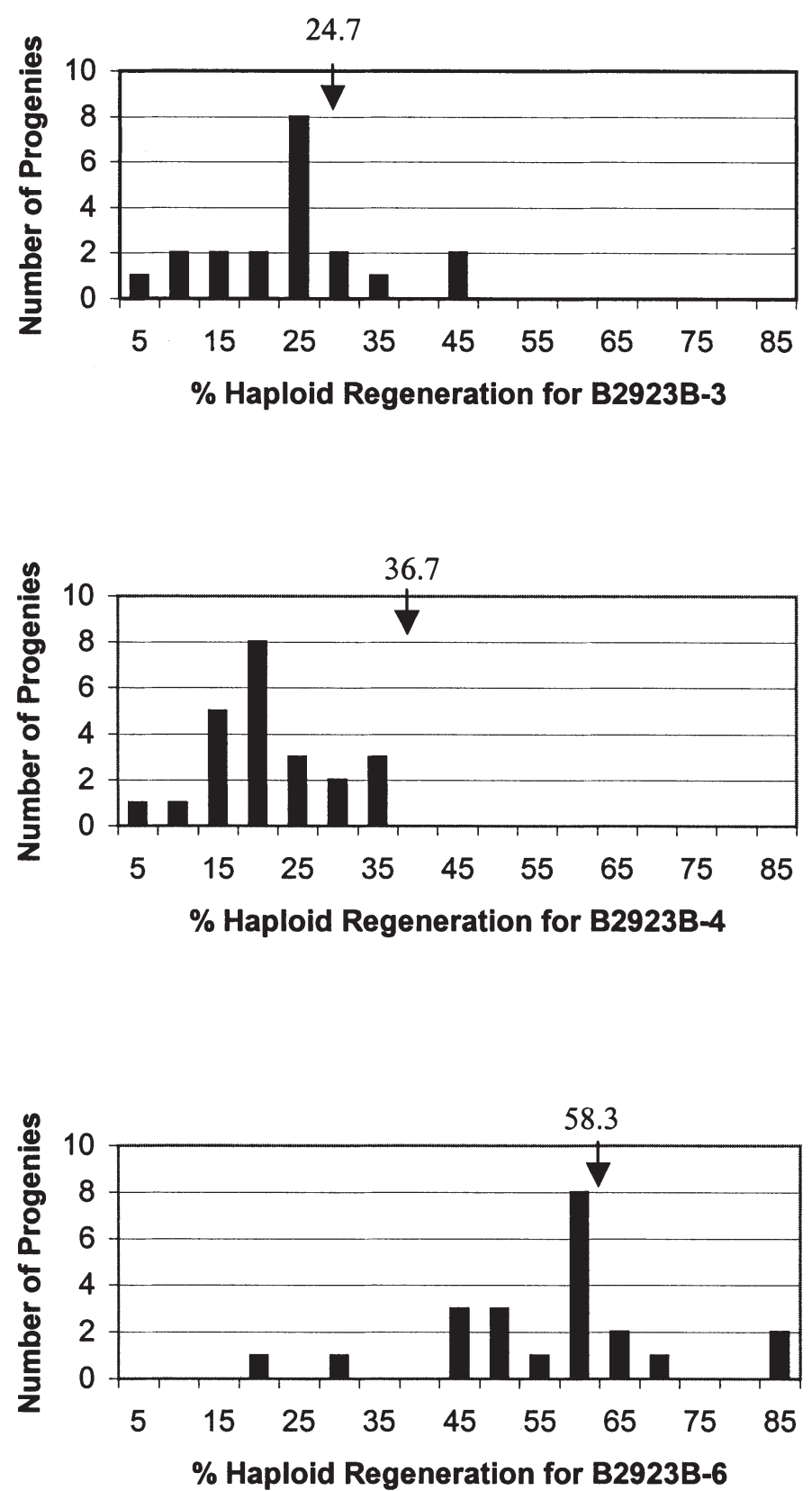

Fig. 1. Histograms showing the percent gynogenic haploid production of $\mathrm{S}_{1}$ progenies from parental plants from inbred B2923B (plants 3, 4, and 6) showing relatively high rates of haploid production (parental values shown at top).

strategy to improve gynogenic haploid production in onion. Onion plants normally produce multiple umbels. One umbel can be used as a source of unpollinated flowers to measure gynogenic haploid production (Bohanec and Jakše, 1999). The remaining umbels on an individual plant can be self-pollinated. $S_{1}$ progenies from highly regenerative parental plants should show relatively high haploid production (Fig. 1, Table 4) and can be intercrossed to produce the next generation. This approach should result in significant response to selection and produce onion populations with higher levels of haploid production.

\section{Literature Cited}

Bohanec, B. and M. Jakše. 1999. Variations in gynogenic response among long-day onion (Allium cepa L.) accessions. Plant Cell Rpt. 18:737-742.

Bohanec, B., M. Jakše, A. Ihan, and B. Javornik. 1995. Studies of gynogenesis in onion (Allium cepa L.): Induction procedures and genetic analysis of regenerants. Plant Sci. 104:215-224.

Campion, B., M. Azzimonti, E. Vicini, M. Schiavi, and A. Falavigna. 1992. Advances in haploid plant induction in onion (Allium cepa L.) through in vitro gynogenesis. Plant Sci. 86:97-104.

Campion, B. and C. Alloni. 1990. Induction of haploid plants in onion ( $\mathrm{Al}$ lium cepa L.) by in vitro culture of unpollinated ovules. Plant, Cell, Tissue Organ Cult. 20:1-6.

Dunstan, D.I. and K. Short. 1977. Improved growth of tissue cultures of onion, Allium cepa. Physiol. Plant. 41:70-72.

Geoffriau, E., R. Kahane, and M. Rancillac. 1997. Variation of gynogenesis ability in onion (Allium cepa L.). Euphytica 94:37-44.

Goldman, I., G. Schroeck, and M.J. Havey. 2000. History of public onion breeding programs and pedigree of public onion germplasm releases in the United States. Plant Breeding Rev. 20:67-103.

Havey, M.J. 1991. History of releases from the onion breeding program of the United States Department of Agriculture. Allium Improvement Nws. 1:50-54.

Havey, M.J. 1993. Onion breeding, p. 35-49. In: G. Kalloo and B. Berg (eds.). Genetic improvement of vegetable crops. Pergamon Press, Oxford.

He, P., L. Shen, C. Lu, Y. Chen, and L. Zhu. 1998. Analysis of quantitative trait loci which contribute to anther culturability in rice (Oryza sativa L.). Mol. Breeding 4:165-171.

Hou, L., S.E. Ullrich, and A. Kleinhofs. 1994. Inheritance of anther culture traits in barley. Crop Sci. 34:1243-1247.

Jakše, M., B. Bohanec, and A. Ihan. 1996. Effect of media components on the gynogenic regeneration of onion (Allium cepa $\mathrm{L}$.) cultivars and analysis of regenerants. Plant Cell Rpt. 15:938-939.

Javornik, B., B. Bohanec, and B. Campion. 1998. Studies on the induction of a second cycle gynogenesis in onion (Allium cepa $\mathrm{L}$.) and genetic analysis of the plants. Plant Breeding 117:275-278.

Keller, J. 1990. Culture of unpollinated ovules, ovaries, and flower buds in some species of the genus Allium and haploid induction via gynogenesis in onion (Allium cepa L.). Euphytica 47:241-247.

Khush, G.S. and S. Virmani. 1996. Haploids in plant breeding, p. 11-33. In: S.M. Jain, S.K. Sopory, and R.E. Veilleux (eds.). In vitro haploid production in higher plants. vol. 1: Dordrecht, London.

King, J.J., J.M. Bradeen, and M.J. Havey. 1998. Variability for RFLPs and relationships among elite commercial inbred and virtual hybrid populations of onion. J. Amer. Soc. Hort. Sci. 123:1034-1037.

Marhic, A., S. Antoine-Michard, J. Bordes, M. Pollacsek, A. Murigneux, and M. Beckert. 1998. Genetic improvement of anther culture response in maize: relationships with molecular, Mendelian and agronomic traits. Theor. Appl. Genet. 97:520-525.

Martinez, L., C. Agüero, M. López, and C. Galmarini. 2000. Improvement of in vitro gynogenesis induction in onion (Allium cepa L.) using polyamines. Plant Sci. 156:221-226.

Michalik, B.,A. Adamus, and E. Nowak. 2000a. Gynogenesis in Polish onion cultivars. J. Plant Physiol. 156:211-216.

Michalik, B., A. Adamus, L. Samek, and E. Nowak. 2000b. Gynogenesis in Polish onion cultivars: effect of temperature during donor plant growth. $\mathrm{p}$. 91-94. In: B. Bohanec (ed.) Biotechnological approaches for utilization of gametic cells. Final COST 824 meeting, Bled, Slovenia.

Muren, R. 1989. Haploid plant induction from unpollinated ovaries in onion. HortScience 24:833-834.

Pike, L.M. 1986. Onion breeding, p. 357-394. In: M.J. Bassett (ed.). Breeding vegetable crops. AVI Publ., Westport, Conn.

Puddephat, I.J., H. Robinson, B. Smith, and J. Lynn. 1999. Influence of stock plant pretreatment on gynogenic embryo induction from flower buds of onion. Plant Cell Tissue Organ Cult. 57:145-148.

SAS Institute. 1990. User's guide: basics and statistics. SAS Institute, Cary, N.C.

Zhou,H.P. and C.F. Konzak. 1992. Genetic control of green plant regeneration from anther culture of wheat. Genome 35:957-961. 